\title{
Land surface conditions over Eurasia and Indian summer monsoon rainfall
}

\author{
Alan Robock and Mingquan $\mathrm{Mu}$ \\ Department of Environmental Sciences, Rutgers University, New Brunswick, New Jersey, USA
}

Konstantin Vinnikov

Department of Meteorology, University of Maryland, College Park, Maryland, USA

David Robinson

Department of Geography, Rutgers University, Piscataway, New Jersey, USA

Received 11 March 2002; revised 8 September 2002; accepted 26 September 2002; published 20 February 2003.

[1] Using observations of snow cover, soil moisture, surface air temperature, atmospheric circulation, and Indian summer monsoon precipitation from 1870 to 2000, we examine the relationship between interannual variations of the strength of the monsoon and land surface conditions over Eurasia. For the periods 1870-1895 and 1950-1995, strong Indian summer monsoon precipitation was preceded by warmer than normal temperatures over Europe and North America in the previous winter and over western Asia in the previous spring but colder temperatures over Tibet. The European temperature anomalies were related to the positive phase of the North Atlantic Oscillation (NAO). Related negative snow cover anomalies in Europe in winter and central Asia in spring were produced by circulation and temperature anomalies. The snow-albedo feedback is always operating, but the snow by itself did not physically control the monsoon. Anomalous snow cover impacts on temperature were not prolonged by soil moisture feedbacks because of its short time memory, and there was no obvious relationship between soil moisture and the monsoon. Strong Indian summer monsoon precipitation was actually preceded by higher than normal Tibetan snow cover in winter and spring in contrast to the suggestion of Blanford [1884] more than a century ago. The correlation between Indian summer monsoon rainfall and winter land temperatures and snow cover only exists when interannual variation of the NAO is very strong, and therefore NAO is not a robust predictor of the monsoon. Climate models show that the relationship between NAO and monsoon is random. INDEX TERMS: 1620 Global Change: Climate dynamics (3309); 1854 Hydrology: Precipitation (3354); 1863 Hydrology: Snow and ice (1827); KEYWORDS: monsoon, snow, soil moisture, NAO, El Niño, India

Citation: Robock, A., M. Mu, K. Vinnikov, and D. Robinson, Land surface conditions over Eurasia and Indian summer monsoon rainfall, J. Geophys. Res., 108(D4), 4131, doi:10.1029/2002JD002286, 2003.

\section{Introduction}

[2] More than 100 years ago, Blanford [1884, p. 22] suggested that winter snow cover over the Himalayas may be an important predictor of subsequent summer precipitation over India. In addition to a local influence that involved dry winds sweeping down from the mountains following each precipitation event that would evaporate the fallen rain at the lower levels, reducing the subsequent local source of moisture for precipitation, he also pointed out that remote influences on the large-scale pressure pattern over India were important. If there was high pressure over India, he concluded that "this excessive pressure was shown to affect

Copyright 2003 by the American Geophysical Union. 0148-0227/03/2002JD002286\$09.00 so extensive a region, that it would be unreasonable to attribute it to the condition of any tract so limited as a portion of the Himalayan chain; and if dependent on the thermal conditions of the surface, which may indeed have been the case, this land must rather have been the major portion of the Asiatic continent than merely a relatively small portion of the mountain axis. This question must remain for further inquiry. It is referred to here to guard against too wide an application being assigned to the action of the Himalayan snows." Here we conduct that further inquiry, making use of a newly extended data set of snow cover extent [Robinson, 2000], the new extended National Centers for Environmental Prediction/National Center for Atmospheric Research (NCEP/NCAR) reanalysis of atmospheric observations [Kistler et al., 2001], tropical sea surface temperatures [Parker et al., 1995] (data available at 
http://www.cru.uea.ac.uk/cru/data/temperature), and the Global Soil Moisture Data Bank [Robock et al., 2000] to examine the relationship between preceding land surface conditions and the amount of summer monsoon precipitation in India.

[3] Blanford [1884] did not suggest that positive snow cover anomalies would increase the surface albedo, delaying heating of the continent or that heavy snow would require more energy to melt the snow, energy that otherwise would have gone to heating the land. Nor did he suggest that snow anomalies would produce soil moisture anomalies with the same effect on surface heating. However, Blanford's work did inspire subsequent research that did lead to these ideas. Bamzai and Shukla [1999, p. 3122] recently examined the spatial pattern of snow cover anomalies and found that the only regions of anomalous snow cover extent that were correlated with Indian summer rainfall were in Europe and western Asia in the preceding winter and spring. They said that a possible explanation for this relationship "is that both the western Eurasian snow cover and the monsoon rainfall anomalies are the results of low-frequency changes in the planetary scale circulation. We do not know of such a low-frequency phenomenon, and therefore we cannot propose this as an explanation for the snow-monsoon relationship." They also suggested that soil moisture interactions would provide a memory from anomalous snow cover that perpetuated the temperature anomaly after the snow melted. Here we address both of these issues, identifying the circulation mechanism and using observations to see whether there is a soil moisture memory.

[4] Shinoda [2001] recently examined the relationship between snow cover and soil moisture in central Asia. While he found a positive relationship for a limited area centered on Uralsk $\left(51^{\circ} \mathrm{N}, 51^{\circ} \mathrm{E}\right)$, in general he found that there was no evidence for a large-scale memory effect that could influence the Asian monsoon. We extend these results by examining a larger number of Asian stations and the direct relationship between soil moisture and the monsoon.

[5] The land-ocean thermal contrast is the primary driver for the Asian monsoon, a seasonal-scale sea breeze circulation [Li and Yanai, 1996; Liu and Yanai, 2001]. Temperature anomalies over land and ocean will both affect the thermal gradient and the strength of the monsoons. Although much work has gone into the oceanic portion of this relationship [Yang and Lau, 1998; Gershunov et al., 2001], here we examine the land portion. In particular, since the well-known correlation with sea surface temperatures (SST) in the Pacific Ocean [Rasmusson and Carpenter, 1983] only appears at the same time as the beginning of the Indian summer monsoon [Clark et al., 2000; Gershunov et al., 2001], and does not allow SST observations to be used to predict the rainfall, we examine land surface processes in the previous winter to try to find predictors of the monsoon.

\section{Data Sets and Methods}

[6] For the analysis presented here, we made use of a number of observational data sets. To represent the Asian summer monsoon, we used all-India rainfall (AIR), an area- weighted average from 29 Indian rainfall subdivisions [Parthasarathy et al., 1995] (data available at http://grads. iges.org/india/partha.subdiv.html). We used the total amount for June, July, August, and September (JJAS); the data are available for 130 years, 1871-2000. Monthly sea level pressure, geopotential height at $500 \mathrm{hPa}$ and $50 \mathrm{hPa}$, and 2-m air temperature were from the NCEP/NCAR Reanalysis [Kistler et al., 2001]. The North Atlantic Oscillation (NAO) [Hurrell, 1995, and references therein] indicates the strength of the zonal wind bringing oceanic air onto the Eurasian continent, producing warmer temperatures in winter when it is positive. To obtain a long record of the NAO, we used the normalized surface pressure difference between Gibraltar and Reykjavik, Iceland [Jones et al., 1997], which extends from 1821 through the present. We analyzed the December, January, and February (DJF) mean.

[7] For representing the influence of oceans on the monsoon, we used a common El Niño index, the seasonal standardized anomaly of SST in the Niño 3.4 region $\left(5^{\circ} \mathrm{N}-\right.$ $\left.5^{\circ} \mathrm{S}, 120^{\circ}-170^{\circ} \mathrm{W}\right)$, calculated using the HadCRUT data set [Parker et al., 1995]. We analyzed the June, July, and August (JJA) mean of the SST anomaly (SSTA), because the highest correlation of SST with AIR is simultaneous.

[8] The soil moisture data are from Global Soil Moisture Data Bank [Robock et al., 2000]. This data bank includes gravimetric measurements at 130 meteorological stations of the former Soviet Union, 102 from China, and 40 from Mongolia of plant available soil moisture for upper $10 \mathrm{~cm}$ and $1 \mathrm{~m}$ soil layers at flat observational plots with natural grass vegetation. The size of the observational plots is about 0.1 ha. Observations were made three times per month during the warm season and once a month during winter. Four points in each plot were used for each measurement and the results averaged. Here we used a subset of these stations for which we also had daily snow depth data. The snow depth data for 1966-1990, from former Soviet Union hydrological snow surveys, were obtained from the National Snow and Ice Data Center.

[9] Northern Hemisphere snow cover extent has been produced by the National Oceanic and Atmospheric Administration. In this analysis, we used monthly data from October 1966 through December 2000, reproduced from weekly charts derived from visual interpretation of photographic copies from visible satellite images [Robinson et al., 1993]. Although the weekly data have some problems, such as low solar illumination, cloudiness, dense forest cover, and subgrid resolution snow features (e.g., in areas of steep terrain), at a monthly resolution these data are suitable for climatic studies.

[10] In this study, we examine the relationship between snow cover, NAO, soil moisture, and AIR using composite and correlation analyses. In the next section, we show the relationship between Eurasian snow cover in the preceding winter and spring and the summer AIR. Then, in section 4, we try to explain what produces snow cover anomalies 3-6 months before anomalies of summer AIR. In section 5, we examine soil moisture memory and whether soil moisture can prolong the snow cover anomaly signal in winter long enough to influence the subsequent summer monsoon. Next we show that the snow cover/soil moisture/monsoon relationships we have described are not robust over the entire climatic record and present climate model simula- 


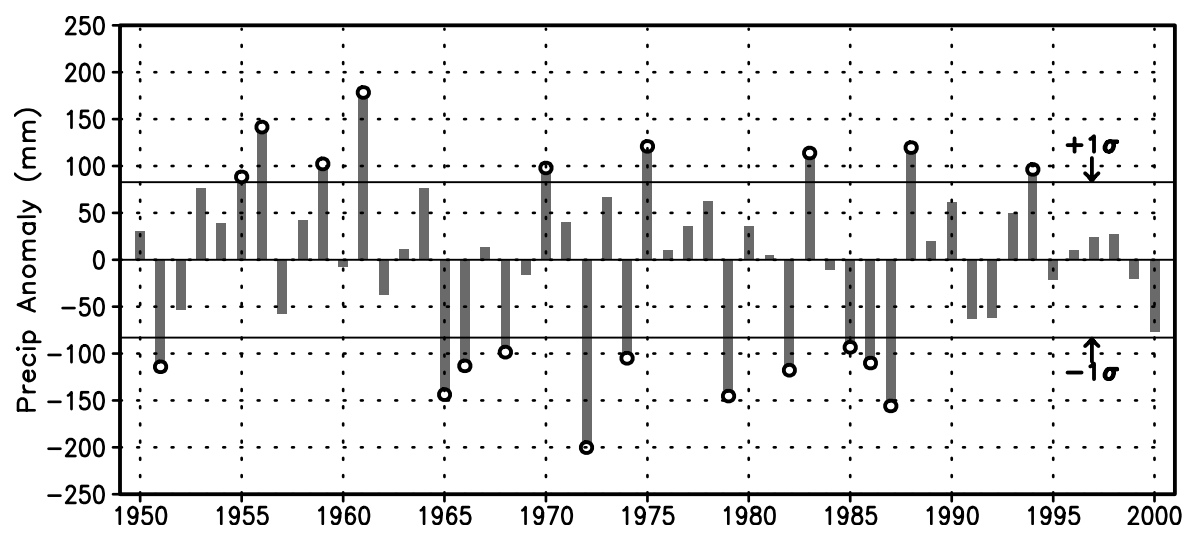

Figure 1. All-India rainfall (AIR) anomaly (mm) in JJAS with respect to 1950-2000 mean. The thin lines show \pm 1 standard deviation. The circles indicate the high and low AIR years used for the composite analyses. See color version of this figure in the HTML.

tions that support this conclusion. Finally, we summarize our study.

\section{Eurasian Snow Cover Patterns Associated With All-India Rainfall}

[11] Figure 1 shows the temporal variation of the summer Indian monsoon rainfall (JJAS AIR) anomaly from 1950 through 2000 . The mean is $847 \mathrm{~mm}$, calculated for the period 1950-2000. For subsequent composite analyses, we defined high AIR to be those years where AIR was more than one standard deviation above the mean $(1955,1956,1959,1961$, $1970,1975,1983,1988$, and 1994) and low AIR to be when it was more than one standard deviation below the mean
(1951, 1965, 1966, 1968, 1972, 1974, 1979, 1982, 1985, 1986, and 1987). While AIR is quite variable, there are fewer negative AIR anomalies during the periods of 1950-1964 and 1988-2000, and the amplitude of AIR variation is very small during the last decade.

[12] To examine the relationship between snow cover and the summer monsoon, we used our new longer snow cover record and performed a composite of five heavy AIR cases minus eight light AIR cases for the period of the snow cover record, 1967-2000, for 2-month winter and spring periods (Figure 2). To examine whether soil moisture could help prolong the snow signal, we also composited the soil moisture differences for 2-month periods following the snow cover periods. Because traditional statistical models cannot
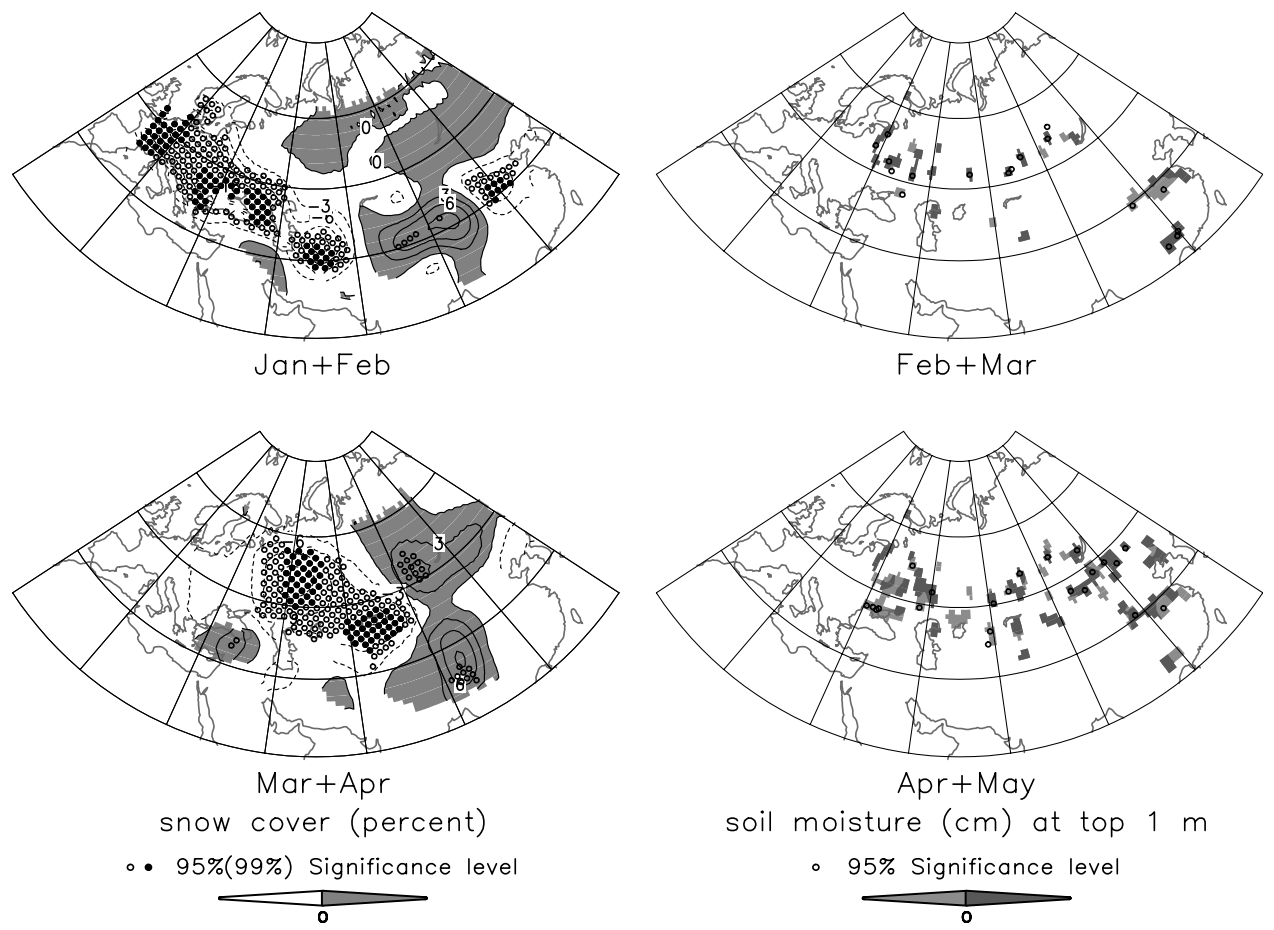

Figure 2. Composites of snow cover and soil moisture patterns for the winters and springs preceding summers of high all-India rainfall minus those of low all-India rainfall for the period 1967-2000. Areas significantly different from zero are stippled. See color version of this figure at back of this issue. 
a
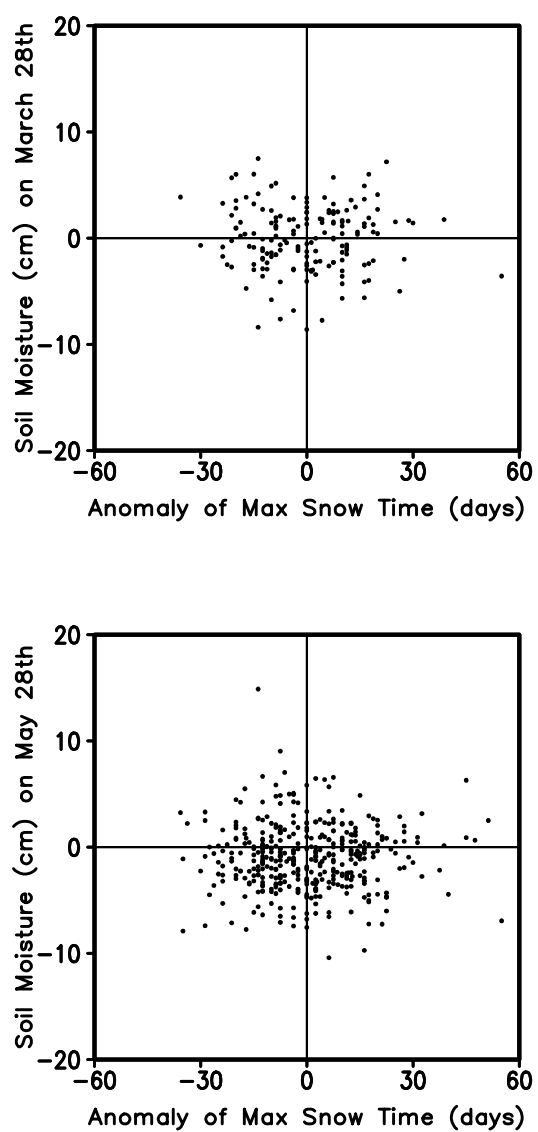

b
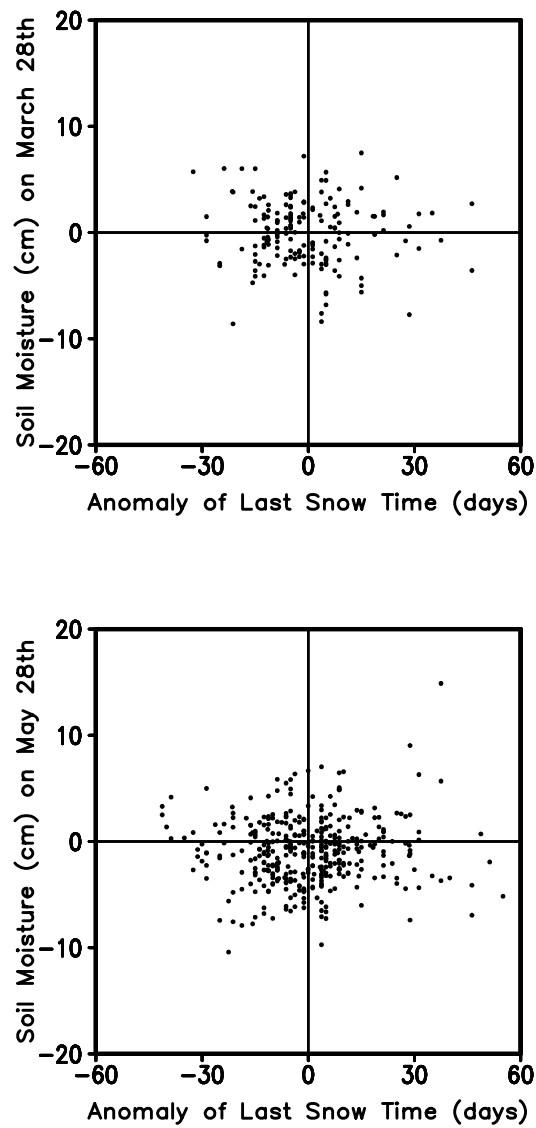
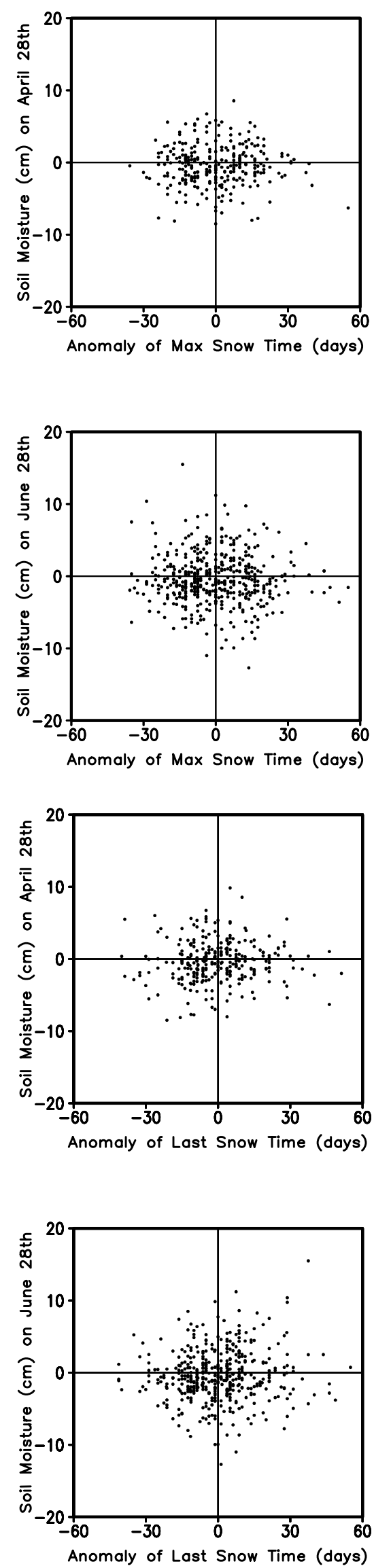


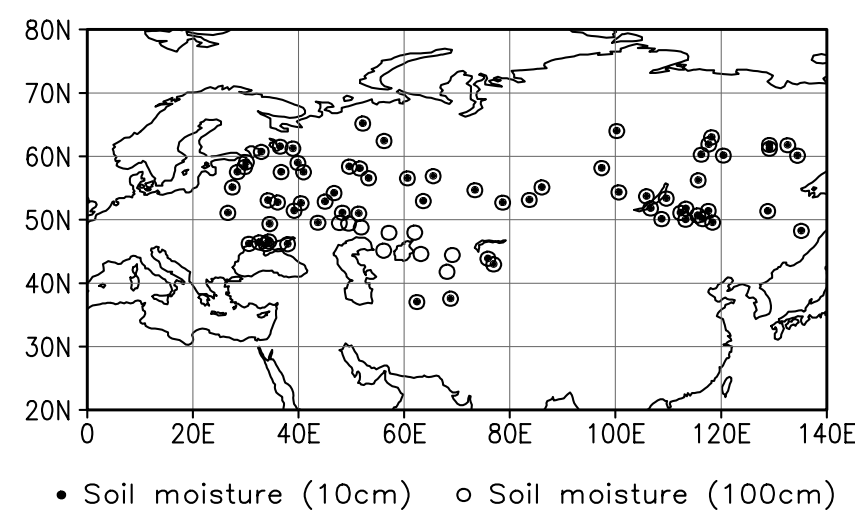

Figure 4. Locations of soil moisture stations for the top 10-cm layer (solid circles) and the top 1-m layer (open circles). See color version of this figure in the HTML.

be used to determine the significance of these patterns, we conducted a Monte Carlo test examining 1000 random combinations of 5 years minus 8 years from the data set, and we show on Figure 2 those locations where the observed difference occurs less than $5 \%$ and less than $1 \%$ of the time by chance [Livezey and Chen, 1983; Robock and Mao, 1995].

[13] The snow cover patterns are highly significant, while the soil moisture ones are not. We can see that snow cover has strong negative anomalies in the middle latitude area of western Eurasia and central Eurasia in the previous winter and spring. Nearly the whole Eurasian continent is covered by negative anomalies of snow cover except the Tibetan area both in the preceding winter and spring of AIR. The patterns are the same as those found by Bamzai and Shukla [1999], who used a shorter time series but also detected a significant positive correlation between Tibetan snow cover and AIR, the opposite of what Blanford suggested for the Himalayas [Blanford, 1884]. This means that heavy Indian summer monsoon rainfall is preceded by lower than normal snow cover in the Eurasian region but by higher than normal snow cover in the Tibetan Plateau for the period of analysis. The snow cover anomalies clearly reflect a wave-like pattern, suggesting a response to circulation anomalies rather than a direct physical influence of the snow on the monsoon circulation.

[14] The composite of soil moisture anomalies shown in Figure 2 shows no particular patterns. Thus the soil moisture is not strongly related to the strength of the Indian summer monsoon. As it does not match the snow patterns, neither is the soil moisture pattern a response to anomalous snow cover. The examination of the relationship between maximum seasonal snow depth amounts just prior to the spring snowmelt and subsequent soil moisture anomalies at each station (not shown) also shows no relationship. In addition, we examined the relationship between both the timing of the spring snow cover peak (the time when melting begins) and the time when all snow is gone (the time when melting ends) and soil moisture amounts in the spring for the top $100 \mathrm{~cm}$ of soil (Figure 3). The results for the top $10 \mathrm{~cm}$ of soil are the same and are not shown. Locations of the stations used for the snow and soil moisture observations are shown in Figure 4. The speculation that an earlier melting would lead to drier soil in the spring (independent of the winter snow amount) is not supported by these results. Similarly, a later snowmelt period does not lead to wetter soil in the spring. There are several reasons to explain this. One is that the ground is often frozen when the snow melts, inhibiting infiltration of the melt water. Another is that the ground is often saturated in the winter in this region, especially in the western part [Robock et al., 1998], and so there is no room in the soil for water to infiltrate. Finally, examination of soil moisture observations for many Russian stations shows that while there is a small spring peak in soil moisture following snowmelt, the level of this peak depends more on the preceding soil moisture amount from the previous winter than on the amount of snowmelt water. In other words, soil moisture memory is prolonged during the cold season when snow covers the soil and there is little change in the soil moisture.

[15] These results are in contrast to climate model experiments [Becker et al., 2001] using the European Centre for Medium-Range Weather Forecasting climate model, which found a large soil moisture signal from melting snow and a subsequent impact on summer Indian monsoon precipitation. This model, however, uses a soil moisture parameterization with a uniform 26-cm field capacity, which is much larger than observed [Robock et al., 1998] and therefore has an unrealistically large capacity for infiltration.

\section{Anomalous Atmospheric Circulation Associated With Eurasian Snow Cover Patterns}

[16] To examine the atmospheric circulation that produces the snow cover patterns shown in Figure 2, we composited the pressure patterns at different levels in the winter (DJF) preceding the Indian summer monsoon for the period 1950-2000 (Figure 5). Significant regions are again shown using a Monte Carlo test. Sea level pressure (SLP) shown in Figure 5 is actually the geopotential height at $1000 \mathrm{hPa}$ $\left(\mathrm{H}_{1000}\right)$ transferred [Thompson and Wallace, 1998] with the formula

$$
\mathrm{SLP}[\mathrm{hPa}]=0.125 \mathrm{H}_{1000}[\mathrm{~m}]+1000 .
$$

The surface air temperature pattern matches that of the positive phase of the Arctic Oscillation (AO) [Thompson and Wallace, 1998], with warm temperatures over North America and northern Eurasia and colder than normal temperatures over Greenland. The circulation patterns in sea level pressure and $500 \mathrm{hPa}$ geopotential height match those of the AO only in the Atlantic sector. This pattern is clearly the North Atlantic Oscillation (NAO) [Hurrell, 1995; Jones et al., 1997], the European manifestation of the

Figure 3. (opposite) Scatter diagram of anomaly of timing of (a) maximum snow depth and (b) first day with no snow compared to the anomaly of soil moisture amount in the top 100-cm soil layer on the last day of the months of March-June for the stations in Figure 4. For the color version, red cross is for snow depth observations before 28 February, green circle is for observations between 28 February and 28 March, blue triangle is for observations for 28 March to 28 April, and yellow square is for observations after 28 April. See color version of this figure in the HTML. 

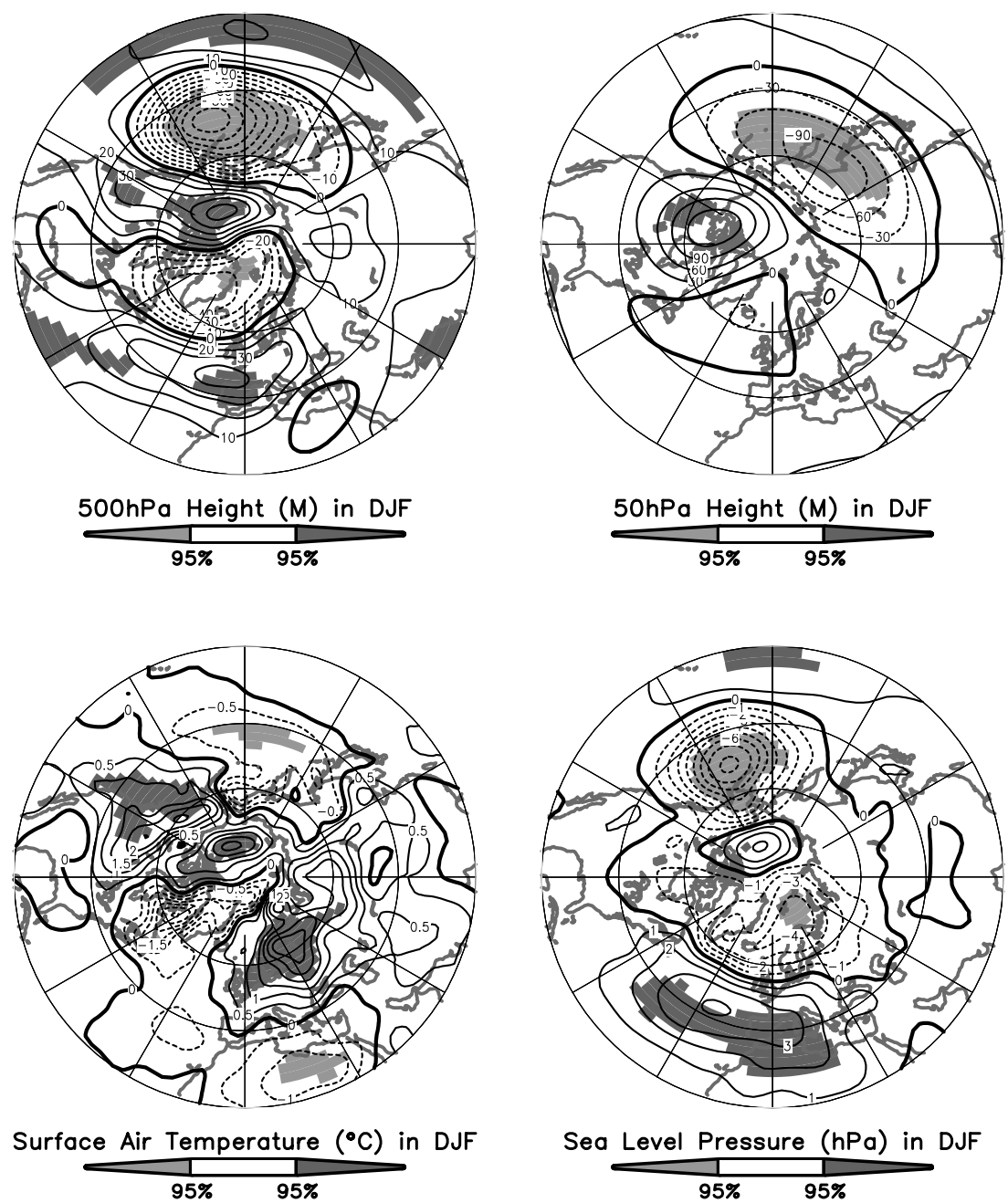

Figure 5. Composites of surface air temperature $\left({ }^{\circ} \mathrm{C}\right)$, sea level pressure $(\mathrm{hPa})$, and $500 \mathrm{hPa}$ and $50 \mathrm{hPa}$ geopotential height $(\mathrm{m})$ patterns for winters (DJF) preceding summers of high all-India rainfall minus those of low all-India rainfall for the period 1950-2000. Areas significantly different from zero are stippled (color version) or shaded (black and white version). See color version of this figure at back of this issue.

AO. The 50-hPa geopotential height does not show a strong polar vortex, a key element of the positive phase of the AO, so this is only a tropospheric manifestation of the NAO circulation anomaly and not related to stratospheric circulation as is the AO. We can also notice that the structure of the atmospheric circulation anomaly has a prominent barotropic character from the bottom (surface air temperature) to the top (geopotential height at $50 \mathrm{hPa}$ ). The pattern in the Pacific sector is similar to the Pacific/North America (PNA) teleconnection pattern [Horel and Wallace, 1981; Wallace and Gutzler, 1981] in all of the geopotential height fields, but this just reflects the close relationship between Indian summer monsoon and El Niño Southern Oscillation (ENSO).

[17] In the spring (March, April, May) the atmospheric circulation continues to stay in a similar pattern as that in winter (DJF). There is still a similar PNA pattern in the Pacific Ocean and NAO pattern in the Atlantic Ocean. Surface air temperature still stays warm in the high and middle latitude region of Eurasia (not shown). The warm land surface will increase the land-ocean thermal contrast in spring, the very important driver to set up the subsequent Indian summer monsoon.

[18] Ambaum et al. [2001] pointed out that the NAO is a more physically relevant and robust mode for Northern Hemisphere atmospheric variability than is the AO. A. S. Bamzai (personal communication, 2002), using a shorter snow cover time series, recently showed that the AO is correlated with the snow cover anomalies and suggested that it could be used as a predictor of Indian monsoon rainfall. However, as we shall see, the relationship described above is a fairly recent development.

[19] What produces the snow cover patterns shown in Figure 2? Clark et al. [1999] recently identified an NAO snow signal in central Europe. Figure 6 confirms this relationship, by showing the correlation coefficient of the DJF NAO index and subsequent snow cover patterns. There is a clear negative snow cover anomaly region associated with the warm temperatures, which moves progressively eastward along the snow boundary from winter into spring. The March/April pattern shows that for warm winters, the springtime snow deficit would allow the snow/albedo feed- 

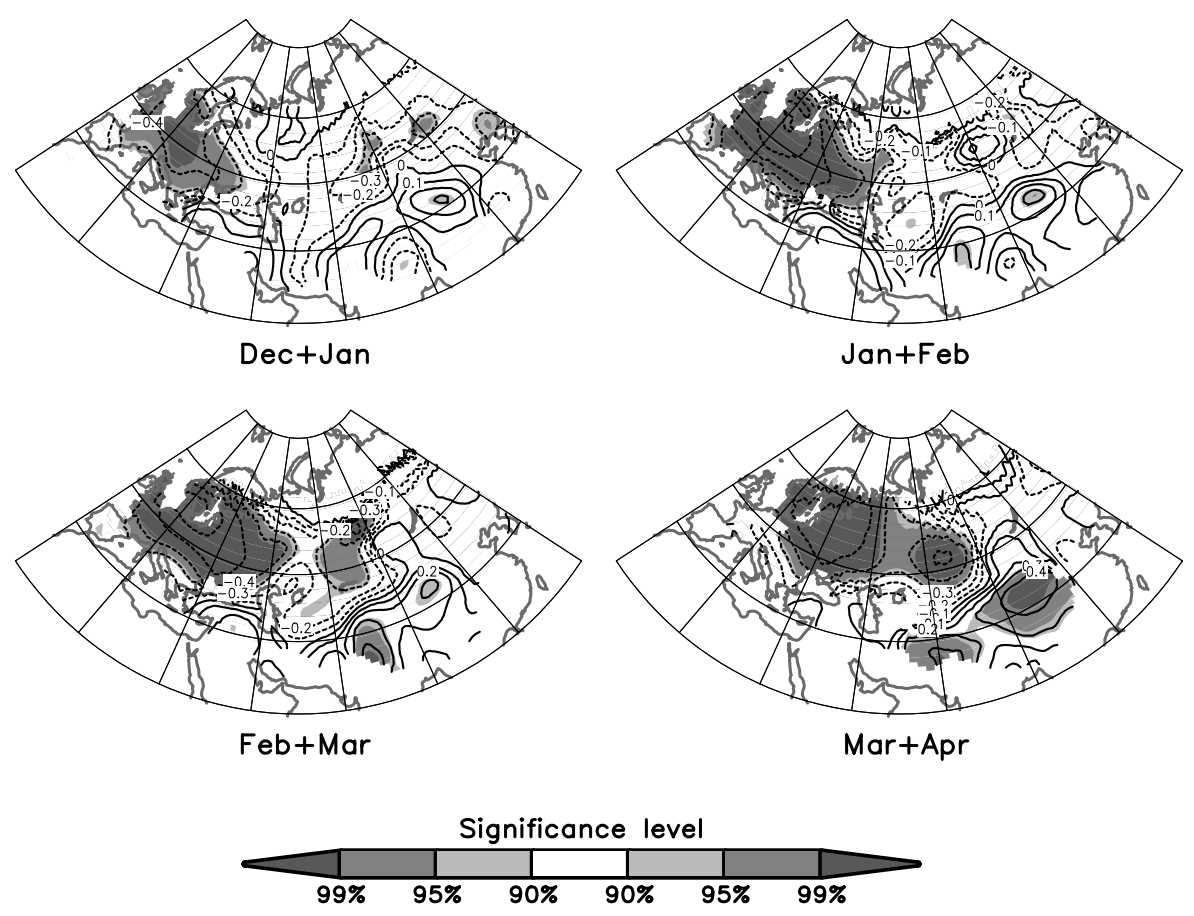

Figure 6. Correlations between detrended snow cover for 2-month periods indicated and the winter (DJF) North Atlantic Oscillation index for the period 1967-2000. Areas significantly different from zero and their significance levels are indicated. See color version of this figure at back of this issue.

back [Schneider and Dickinson, 1974; Robock, 1983] to warm the northern Asian land mass earlier than for years without this NAO anomaly. At the same time, there is a significant positive snow cover anomaly over Tibet and the Himalayas. This wave-like circulation feature implies that a large-scale wind pattern is influencing the temperature and snow cover patterns and probably in turn is influenced by the snow. However, a simple thermal control of the entire monsoon initiation process by Himalayan and Tibetan snow cover [Blanford, 1884] is not supported by this pattern.

\section{Soil Moisture Memory}

[20] To examine whether soil moisture anomalies can prolong the snow cover anomalies shown above so as to influence summer land temperature, we examined stations with both snow and soil moisture observations. We looked at the relationship between soil moisture at the time of snow disappearance to see for how long any soil moisture anomalies would persist. We used 67 stations with upper $10-\mathrm{cm}$ layer soil moisture and 76 stations with upper 1-m soil moisture (Figure 4). For each station, soil moisture was observed on the 8 th, 18 th, and 28 th of each month.

[21] Figure 7 shows scatterplots for the soil moisture anomalies (with respect to the 1978-1985 monthly mean) at the time of snowmelt with lagged soil moisture for the upper 10-cm layer with lags of 10, 20, 30, and 40 days. It is clear that there is some memory up to about 30 days but none beyond that. The top $1-\mathrm{m}$ soil moisture has a longer memory (Figure 8) but less than 2 months. These results are consistent with the temporal scales of soil moisture found previously for the entire data set [Vinnikov et al., 1996; Entin et al., 2000]. For winter snow anomalies to influence the summer monsoon through soil moisture memory, the snow signal must be preserved in the soil for at least 3 months. The results here give no support for this mechanism.

[22] Matsuyama and Masuda [1998] found a weak relationship between central Asian soil moisture and subsequent Indian monsoon rainfall but only examined four years and found the relationship in three of those years. This result is not statistically robust, and they did not claim that it was.

\section{Decadal Changes of Relationship Between NAO and AIR}

[23] Blanford [1884] found a correlation with snow similar to what we showed above in section 4, and subsequently Himalayan snow was used as a predictor of AIR by the Indian Meteorological Department, based on the work of Walker [1910]. While this relationship proved useful in predicting Indian summer rainfall in the first part of this century, the relationship did not seem to work after 1920 and was abandoned as a predictor until the relationship was rediscovered by Hahn and Shukla [1976], the first to use hemispheric snow cover data from satellites to verify the Blanford relationship. The current Indian Meteorological Department regression forecast for the Indian summer monsoon uses snow cover as one of 16 predictors [Gowariker et al., 1989, 1991]. How has the relationship between snow cover and Indian monsoon rainfall changed over time, and can it be used as a robust predictor?

[24] We examined the relationship between land, ocean, and summer monsoon rainfall for the period 1871-2000 using AIR, NAO, and SST time series described in section 2. Because satellite snow cover data do not exist before 1966, and homogenous station records of snow in Eurasia are also 

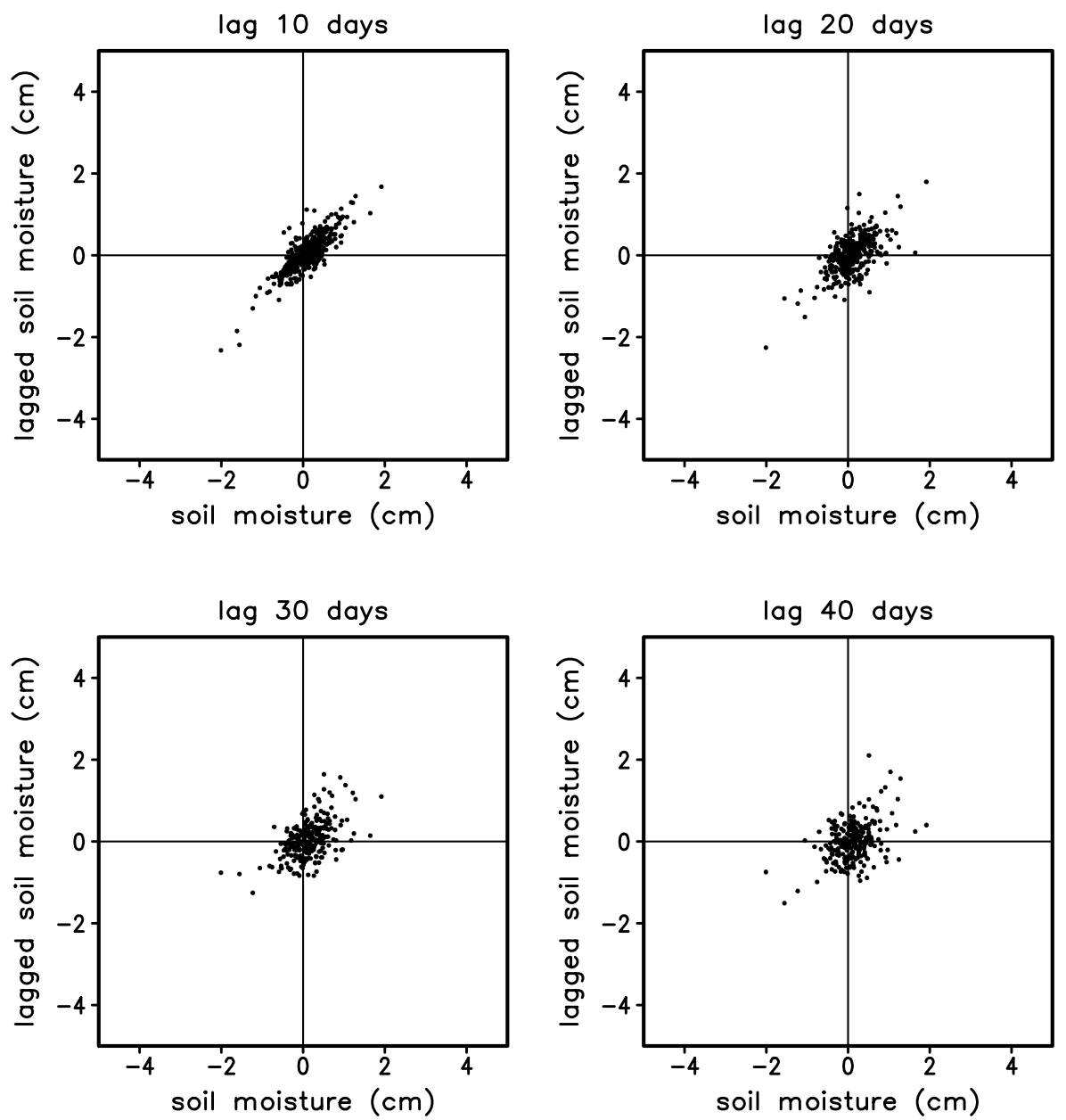

Figure 7. Scatterplots of soil moisture anomalies (cm) with respect to 1978-1985 monthly mean in the top $10-\mathrm{cm}$ soil layer at the time of snowmelt with respect to the lagged soil moisture at the same station for the stations shown in Figure 4. See color version of this figure in the HTML.

not available, we take advantage of the relationship between NAO and snow cover shown in Figure 6 and use NAO as a proxy for Eurasian snow. We examined anomalies with respect to $1871-2000$ means for all the data.

[25] Figure 9 shows the temporal variations of the correlation coefficients between AIR and the NAO index (top) and between AIR and Niño 3.4 SSTA (bottom) for 11-year and 21-year sliding windows. The relationship between simultaneous Niño 3.4 SSTA and AIR had a significant negative correlation for the entire period, averaging about -0.6 , with the exception of the past decade. This recent decrease was noted by Chang et al. [2001], who examined only the past 60 years. The correlation between the previous winter NAO index and AIR has a much more interesting and variable relationship. They have been significantly positively correlated only for the period from the 1960s to 1990. The only other time the correlation was this high was in the 1880s, precisely the time when Blanford [1884] wrote his paper! In between, the correlation was not significant, except for a brief period, 1910-1930, when it was significantly negative. In the 1990 s the positive correlation became insignificant, as did the one with SSTA.

[26] How can we explain the relationships found in Figure 9? Clearly, we do not expect land temperature anomalies (as indicated by winter snow) or sea surface temperature anomalies to be the only influences on the summer monsoon. The winter snow may indicate a circulation anomaly related to many other factors and not summer land temperature, and certainly there are stochastic elements to the relationship. However, if the land or ocean has large interannual variance for a period, then one would think it would be able to have a larger influence than if it were close to its normal state. Therefore we examined the temporal variations of the standard deviations of AIR, Niño 3.4 SSTA, and NAO index (Figure 10). The standard deviation of SSTA is nearly a constant for the entire record, with the exception of the period near World War II, which is clearly a data problem. AIR and NAO variances, however, have clear interdecadal variations. Only during the periods when both have a high variability (1880s and 1960s to 1990) is there a significant positive correlation between them (Figure 9). This suggests that there is a relationship between winter circulation and summer monsoon, but that it is only strong enough to be important when there is large interannual variability. As the interannual variability of AIR has decreased in the 1990s to levels only seen before in the 1930s (Figure 10 of this paper and Figure 4 of Vinnikov and Robock [2002]), the correlation between AIR and SSTA has gone away (Figure 9). 

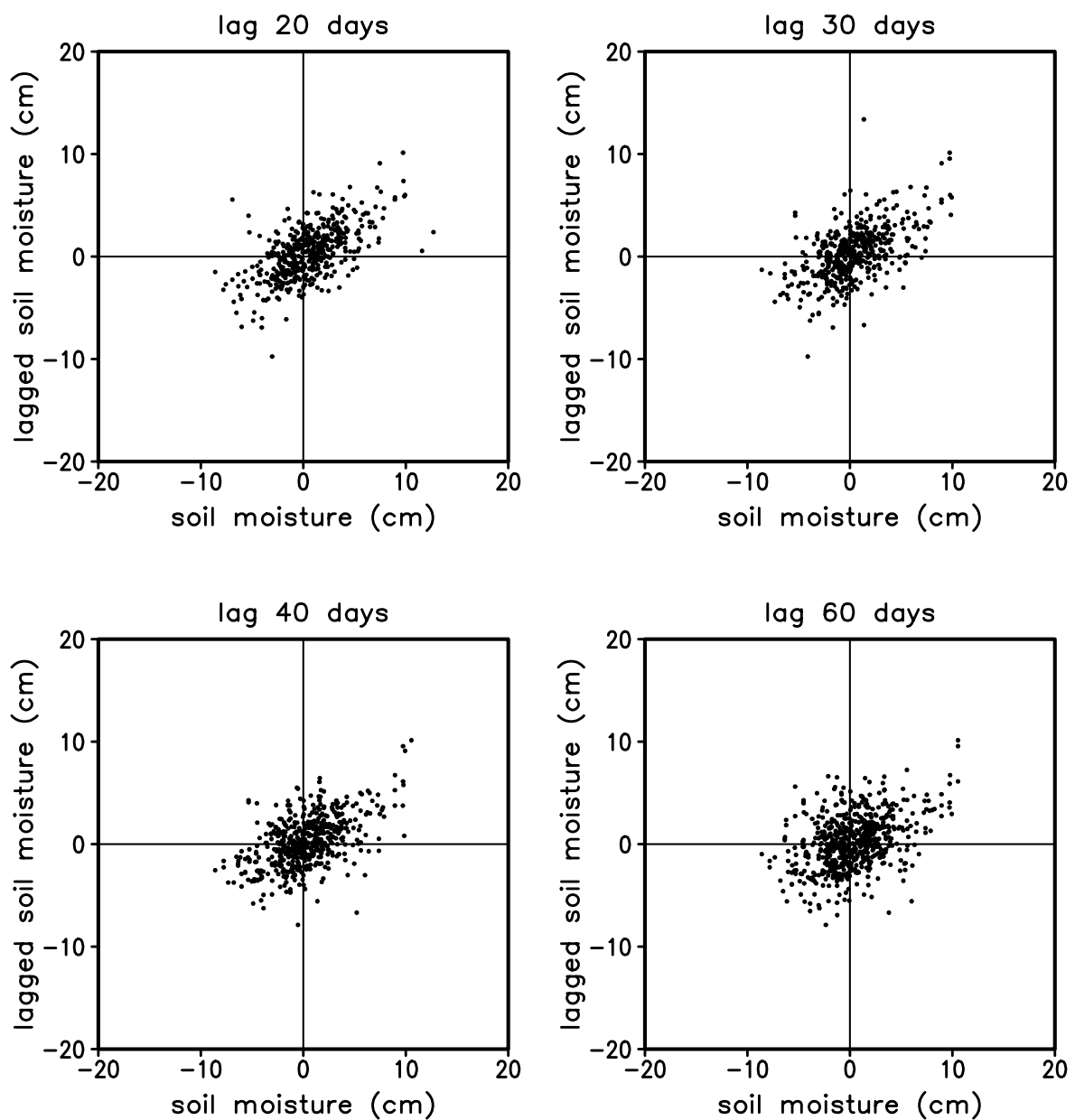

Figure 8. Same as Figure 7, but for the top 1-m layer with lags of 20, 30, 40, and 60 days. See color version of this figure in the HTML.

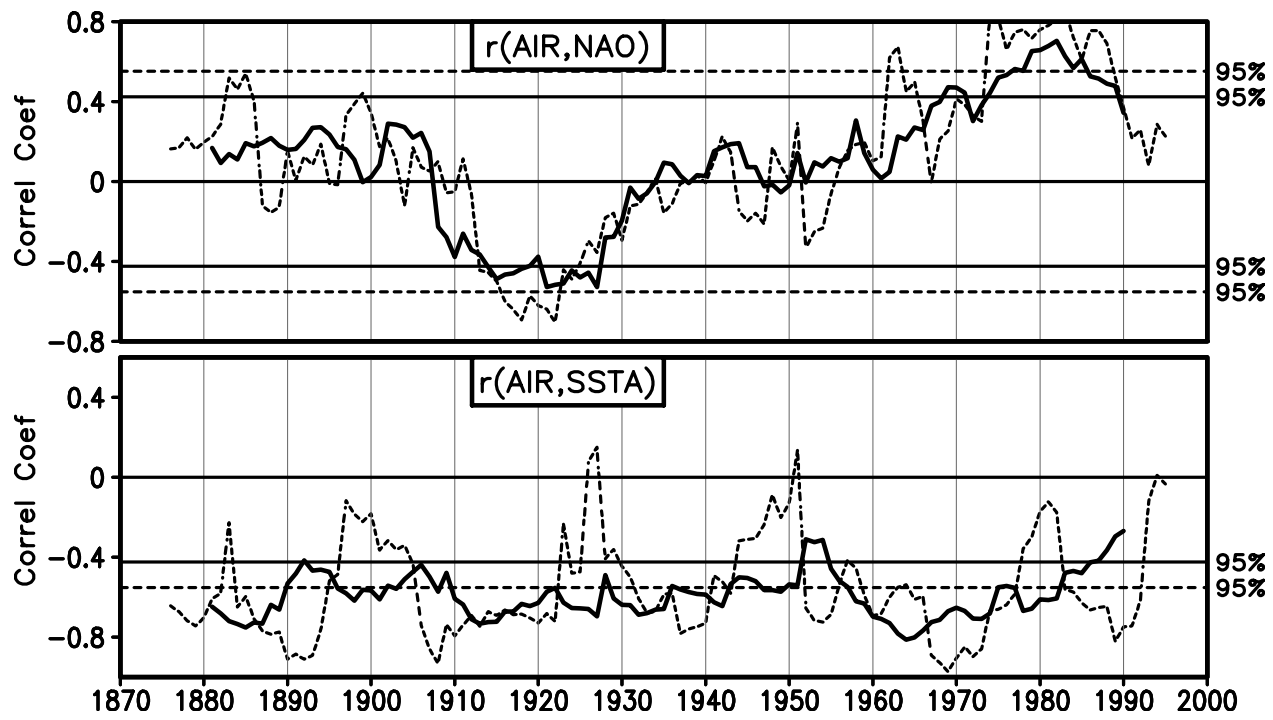

Figure 9. Correlation coefficients between (top) JJAS AIR and DJF North Atlantic Oscillation (NAO) index and (bottom) JJAS AIR and JJA Niño 3.4 SSTA for 11-year (the thin dashed curves) and 21-year (the bold solid curves) sliding windows. All of the data were detrended within each window before calculating the correlation. The thin solid and dashed lines indicate the 95\% significance level. See color version of this figure in the HTML. 

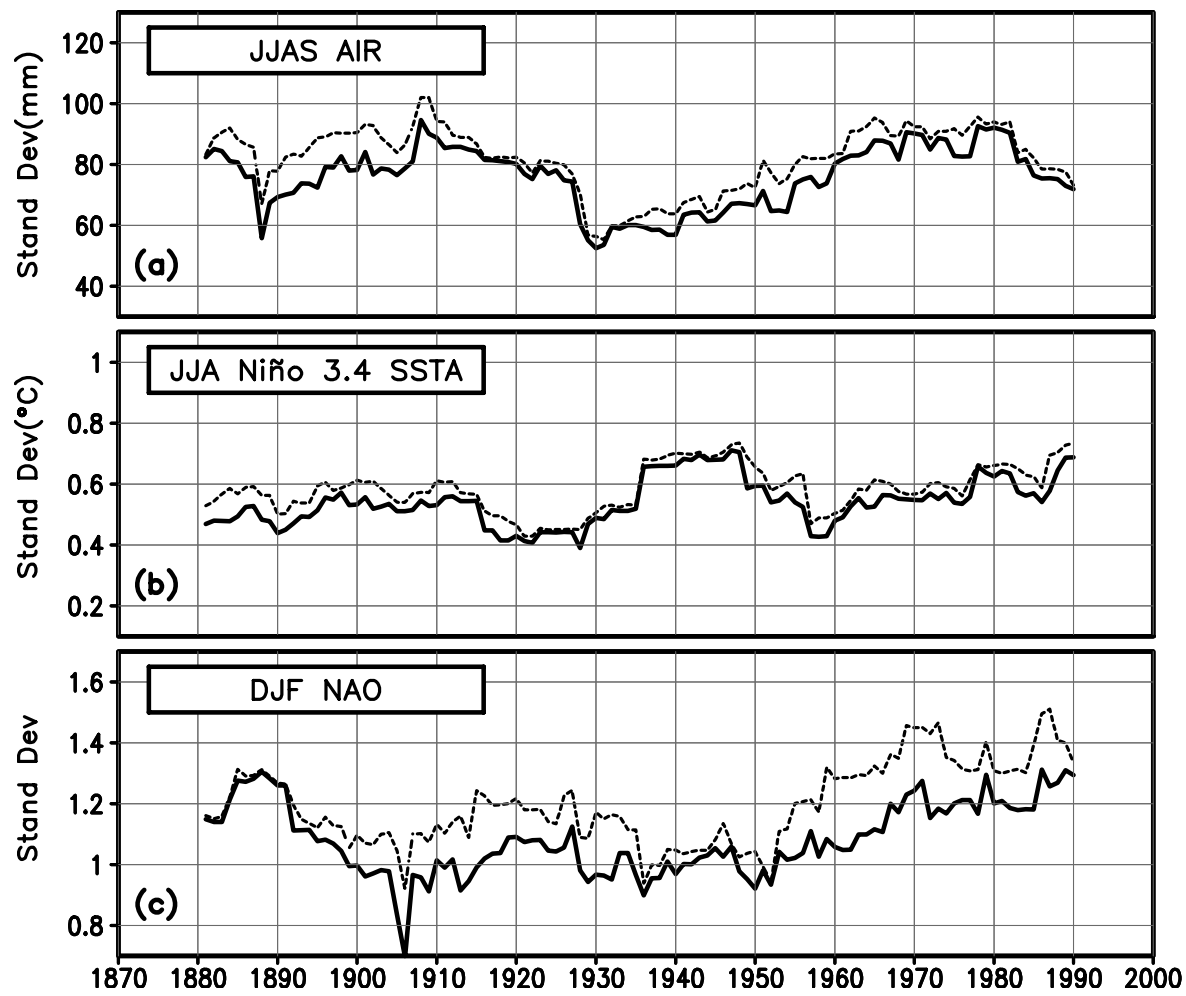

Figure 10. Standard deviations of (a) JJAS AIR, (b) JJA Niño 3.4 SSTA, and (c) DJF NAO index for 21-year sliding windows. All data are with respect to 1871-2000 mean. The thick black curves are detrended within each 21-year window, but the thin dashed ones are not. See color version of this figure in the HTML.

[27] To further investigate the reasons for the changing relationship between the NAO and Indian monsoon rainfall, we looked at general circulation model (GCM) simulations of the past century and future projections of climate due to changing greenhouse gases and tropospheric aerosols (Table 1). Output from the Geophysical Fluid Dynamics Laboratory runs was obtained from their web site (http:// www.gfdl.noaa.gov), and the other GCM runs were obtained from the Intergovernmental Panel on Climate Change (IPCC) Data Distribution Centre (http://ipccddc.cru.uea.ac.uk/). All models were forced with observed equivalent $\mathrm{CO}_{2}$ and tropospheric aerosols since 1850 and one of two IPCC projections for the future [Houghton et al., 1994], IS92a (1\% increase of $\mathrm{CO}_{2}$ per year) or IS92d (a slower emissions growth rate). All models also conducted control simulations, with forcing fixed at preindustrial levels, to examine natural internally generated climate change.

[28] For both the control runs (Figure 11) and the scenario runs (Figure 12), occasionally the 21-year running mean correlation of NAO and AIR appears significantly positive or negative but with no apparent pattern. From this we conclude that the observed correlation is also a random pattern, induced by natural variability. While some of the time series of the forced runs (Figure 12) are significantly positive in the period $1980-2000$, several are also at this level in 1920 when the observations are significantly negative. Results using different periods for running means (not shown) are similar.

[29] We obtained the most recent, readily available output of both control and scenario runs from a sampling of the best climate modeling groups in the world. Other such

Table 1. List of General Circulation Models Used in Figures $11-12^{\mathrm{a}}$

\begin{tabular}{llcc}
\hline Model Version & \multicolumn{1}{c}{ Modeling Group } & Scenario & Reference \\
\hline GFDL_R30_c & $\begin{array}{l}\text { Geophysical Fluid Dynamics Laboratory, } \\
\text { Princeton, New Jersey } \\
\text { ECHAM3/LSG }\end{array}$ & IS92d & Delworth et al. [2002] \\
Hamburg, Germany & IS92a & Cubasch et al. [1997] \\
HADCM2 & $\begin{array}{l}\text { Hadley Centre for Climate Prediction } \\
\text { and Research, Bracknell, }\end{array}$ & IS92d & Johns et al. [1997] \\
United Kingdom & $\begin{array}{l}\text { National Center for Atmospheric Research, } \\
\text { NCAR1 }\end{array}$ & IS92a & Meehl et al. [1996] \\
\hline
\end{tabular}

${ }^{\mathrm{a}}$ All were run in control mode and with observed equivalent $\mathrm{CO}_{2}$ and tropospheric aerosols for the past and with the specified future forcing scenario [Houghton et al., 1994]. 


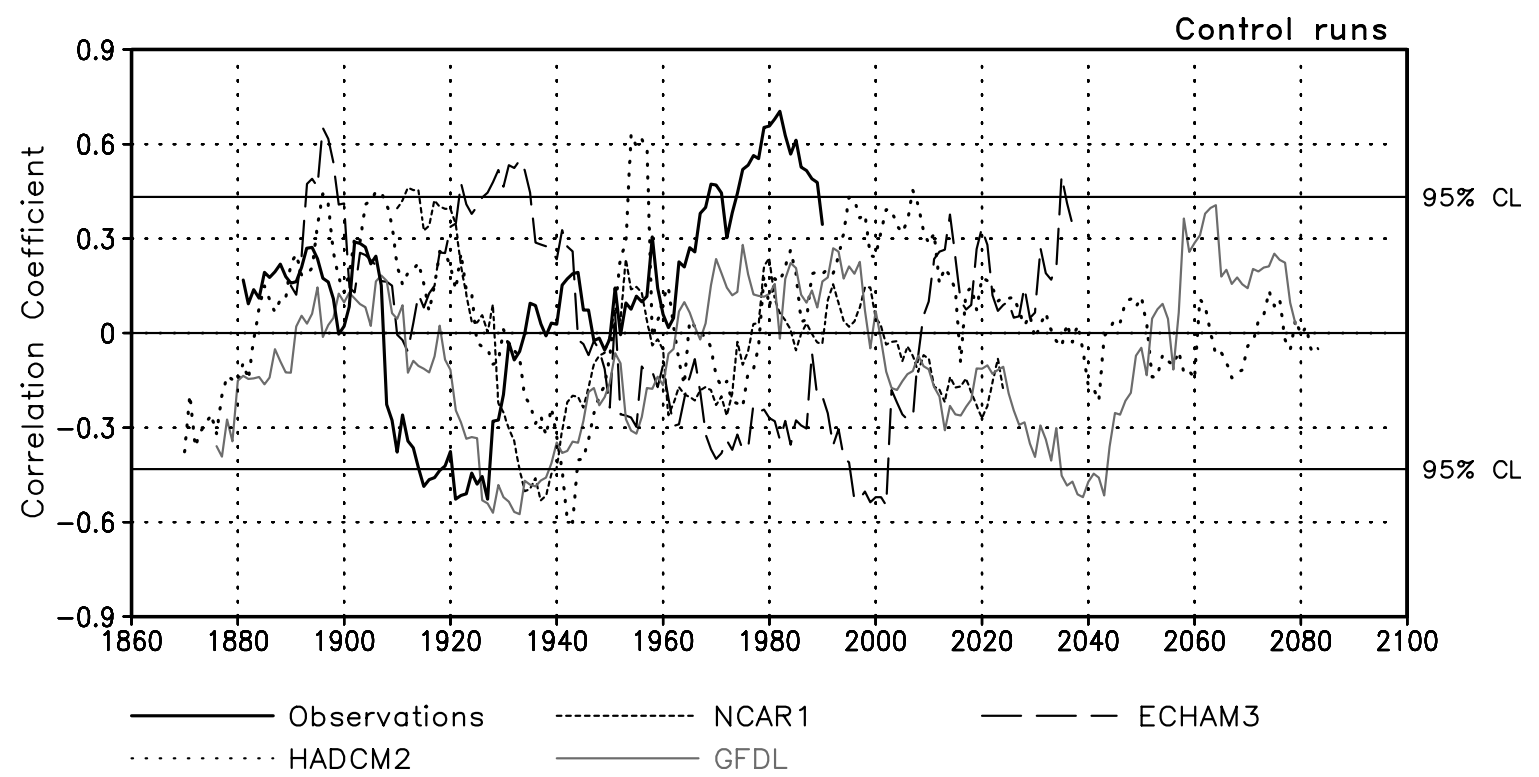

Figure 11. The 21-year running mean correlation between NAO and AIR for observations (repeating curve in Figure 9) and for control runs of four general circulation models (GCMs) (Table 1). See color version of this figure at back of this issue.

model simulations have been conducted, and more recent versions of some these models are now being used. Results from improved models may change the conclusions here, but that analysis is for future work.

\section{Summary and Discussion}

[30] All the snow cover patterns shown here are by necessity along the edge of the winter snow pack, where snow cover varies from one year to the next. Snow depth might vary in the interior of the snow cover without affecting the extent. However, Kripalani and Kulkarni [1999] used snow depth data for the former Soviet Union and produced patterns very similar to the snow cover patterns shown by us and by Bamzai and Shukla [1999], so the use of snow extent should not be a limiting factor in our discussion.

[31] Liu and Yanai [2001] have recently shown that simultaneous tropospheric temperatures over Eurasia and tropical convection over Africa are related to the amount of Indian summer monsoon rainfall. They did not find a strong

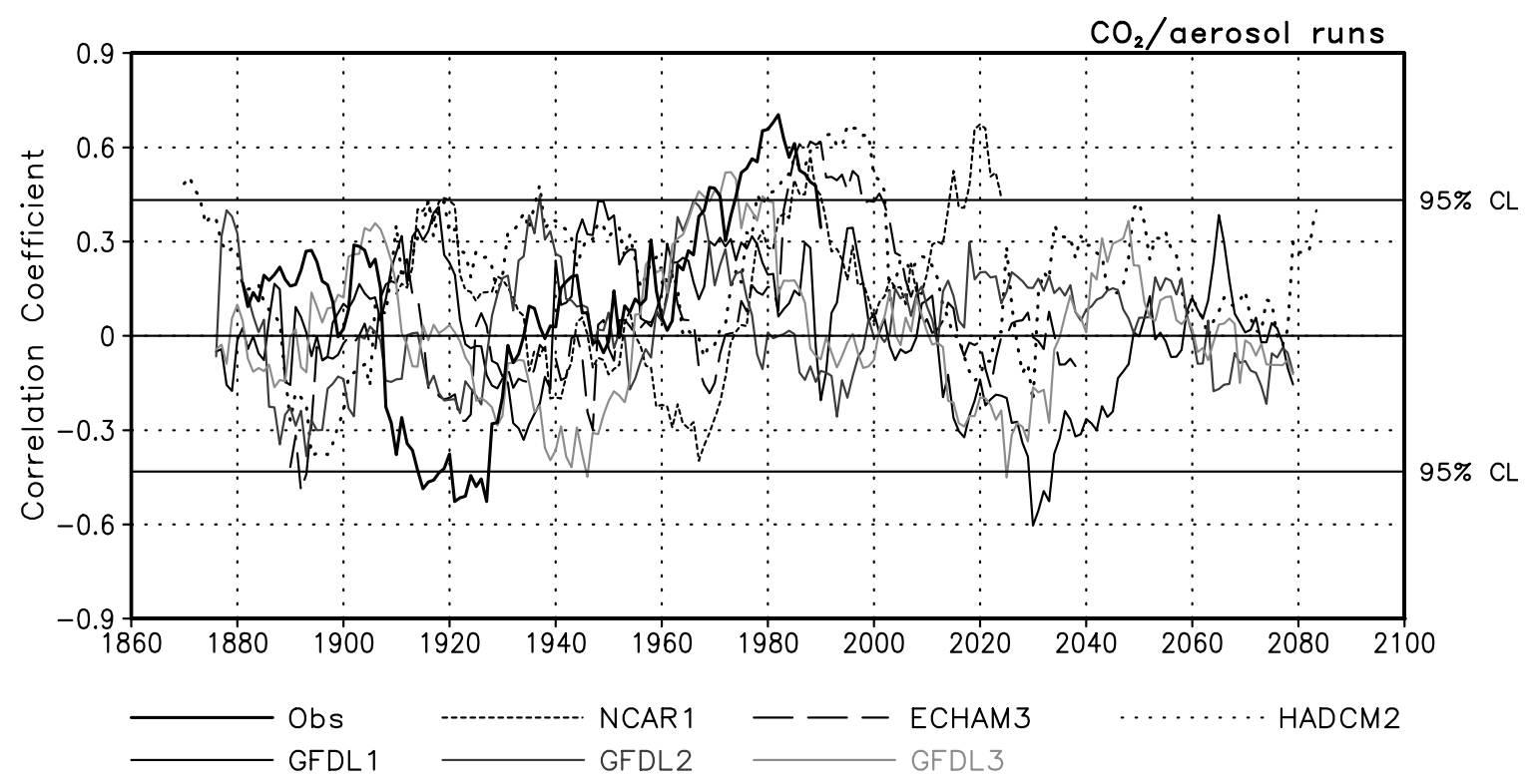

Figure 12. The 21-year running mean correlation between NAO and AIR for observations (repeating curve in Figure 9) and for runs of four GCMs (Table 1) forced with observed equivalent $\mathrm{CO}_{2}$ and tropospheric aerosols for the past and Intergovernmental Panel on Climate Change scenarios (Table 1) [Houghton et al., 1994] for the future. Three different Geophysical Fluid Dynamics Laboratory ensemble members are shown. See color version of this figure at back of this issue. 
relationship between spring Eurasian surface temperatures and the summer monsoon and suggest that therefore summer sea surface temperatures play the strongest role. Nevertheless, the winter snow cover and atmospheric circulation precursors we found here must exert their influence through some physical energy storage mechanism in the climate system. This mechanism remains to be explained.

[32] Because soil moisture memory is very short, we cannot use soil moisture as a bridge to link snow cover in the winter and the subsequent Indian summer monsoon, as suggested by Bamzai and Shukla [1999]. Then how can we explain the close relationship between the preceding winter and spring snow cover and Indian summer monsoon rainfall for some periods? Anomalous atmospheric circulation in the previous winter and spring may play an important role in the development of the land-ocean thermal contrast before the Indian summer monsoon. However, why does the atmospheric circulation anomaly persist for so long from the winter through the spring? Does the snow-albedo feedback [Barnett et al., 1989; Yasunari et al., 1991] or snow-circulation interaction [Cohen and Entekhabi, 1999] produce this result? This needs further study.

[33] Kumar et al. [1999] and Chang et al. [2001] both noted the decreasing relationship between AIR and JJA SSTA in the Niño 3.4 region in the recent several decades. They attribute it to global warming, as manifested by the global temperature trends and tendency of NAO to be in a more positive mode the past several decades. By examining data for a much longer period, we present a larger perspective on this issue. Since the high correlation of AIR with NAO began in the 1960s, but the weak correlation of AIR with SSTA only began after 1980, the weakening relationship between AIR and SSTA cannot be simply attributed to disturbance by the NAO. For the past 20 years, neither has been highly correlated with AIR. Also, climate model simulations do not show an upward trend in NAO-AIR correlations induced by global warming nor a consistent pattern in response to climate change.

[34] As the strength of the monsoon is influenced by the difference between the land and the ocean thermal conditions, it is not unexpected for the SSTs to play a role. However, it is surprising that this data analysis shows such a prominent role for the land in the recent several decades and provides an index half a year in advance that is related to the summer monsoon. However, this situation has changed in the past 2 decades. Clearly, more work is needed to explain these relationships.

[35] Acknowledgments. We thank Anjuli Bamzai, G. Srinivasan, Georgiy Stenchikov, the reviewers, and the Editor for valuable comments on the manuscript. This work was supported by NSF grant ATM-0083165.

\section{References}

Ambaum, M. H. P., B. J. Hoskins, and D. B. Stephenson, Arctic oscillation or North Atlantic Oscillation?, J. Clim., 14, 3495-3507, 2001.

Bamzai, A. S., and J. Shukla, Relation between Eurasian snow cover, snow depth, and the Indian summer monsoon: An observational study, J. Clim., 12, 3117-3132, 1999.

Barnett, T. P., L. Dumenil, U. Schlese, E. Roeckner, and M. Latif, The effect of Eurasian snow cover on regional and global climate variations, J. Atmos. Sci., 46, 661-685, 1989.

Becker, B. D., J. M. Slingo, L. Ferranti, and F. Molteni, Seasonal predictability of the Indian summer monsoon: What role do land-surface conditions play?, Mausam, 52, 175-190, 2001.
Blanford, H. F., On the connexion of the Himalaya snowfall with dry winds and seasons of drought in India, Proc. R. Soc. London, 37, 1-23, 1884. Chang, C.-P., P. Harr, and J. Ju, Possible roles of Atlantic circulations on the weakening Indian monsoon rainfall-ENSO relationship, J. Clim., 14, 2376-2380, 2001.

Clark, C. O., J. E. Cole, and P. J. Webster, Indian Ocean SST and Indian summer rainfall: Predictive relationships and their decadal variability, J. Clim., 13, 2503-2519, 2000

Clark, M. P., M. C. Serreze, and D. A. Robinson, Atmospheric controls on Eurasian snow extent, Int. J. Climatol., 19, 27-40, 1999.

Cohen, J., and D. Entekhabi, Eurasian snow cover variability and Northern Hemisphere climate predictability, Geophys. Res. Lett., 26, 345-348, 1999.

Cubasch, U., R. Voss, G. C. Hegerl, J. Waszkewitz, and T. J. Crowley, Simulation of the influence of solar radiation variations on the global climate with an ocean-atmosphere general circulation model, Clim. Dyn., 13, 757-767, 1997.

Delworth, T. L., R. J. Stouffer, K. W. Dixon, M. J. Spelman, T. R. Knutson, A. J. Broccoli, P. J. Kushner, and R. T. Wetherald, Simulation of climate variability and change by the GFDL R30 coupled climate model, Clim. Dyn., 19, 555-574, 2002.

Entin, J. K., A. Robock, K. Y. Vinnikov, S. E. Hollinger, S. Liu, and A. Namkhai, Temporal and spatial scales of observed soil moisture variations in the extratropics, J. Geophys. Res., 105, 11,865-11,877, 2000.

Gershunov, A., N. Schneider, and T. Barnett, Low-frequency modulation of the ENSO-Indian monsoon rainfall relationship: Signal or noise?, J. Clim., 14, 2486-2492, 2001.

Gowariker, V., V. Thapliyal, R. P. Sarkeer, G. S. Mandal, and D. R. Sikka, Parametric and power regression models: New approach to long range forecasting of monsoon rainfall in India, Mausam, 40, 115-122, 1989.

Gowariker, V., V. Thapliyal, S. M. Kulshrestha, G. S. Mandal, N. Sen Roy, and D. R. Sikka, A power regression model for long range forecast of southwest monsoon rainfall over India, Mausam, 42, 125-130, 1991.

Hahn, D. G., and J. Shukla, An apparent relationship between the Eurasian snow cover and Indian monsoon rainfall, J. Atmos. Sci., 33, 2461-2462, 1976.

Horel, J. D., and J. M. Wallace, Planetary-scale atmospheric phenomena associated with the Southern Oscillation, Mon. Weather Rev., 109, 813829,1981

Houghton, J. T., L. G. Meira Filho, J. Bruce, H. Lee, B. A. Callender, E. Haites, N. Harris, and K. Maskell (Eds.), Radiative Forcing of Climate Change and an Evaluation of the IPCC IS92 Emissions Scenarios, 339 pp., Cambridge Univ. Press, New York, 1994.

Hurrell, J. W., Decadal trends in the North Atlantic Oscillation: Regional temperatures and precipitation, Science, 269, 676-679, 1995.

Johns, T. C., R. E. Carnell, J. F. Crossley, J. M. Gregory, J. F. B. Mitchell, C. A. Senior, S. F. B. Tett, and R. A. Wood, The second Hadley Centre coupled ocean-atmosphere GCM: Model description, spinup and validation, Clim. Dyn., 13, 103-134, 1997.

Jones, P. D., T. Jonsson, and D. Wheeler, Extension to the North Atlantic Oscillation using early instrumental pressure observations from Gibraltar and south-west Iceland, Int. J. Climatol., 17, 1433-1450, 1997.

Kistler, R., et al., The NCEP-NCAR 50-year reanalysis: Monthly means CD-ROM and documentation, Bull. Am. Meteorol. Soc., 82, 247-267, 2001.

Kripalani, R. H., and A. Kulkarni, Climatology and variability of historical Soviet snow depth data: Some new perspective in snow-Indian monsoon teleconnections, Clim. Dyn., 15, 475-489, 1999.

Kumar, K. K., B. Rajagopalan, and M. A. Cane, On the weakening relationship between the Indian monsoon and ENSO, Science, 284, 2156-2159, 1999.

Li, C., and M. Yanai, The onset and international variability of the Asian summer monsoon in relation to land-sea thermal contrast, J. Clim., 9, 358-375, 1996

Liu, X., and M. Yanai, Relationship between the Indian monsoon rainfall and the tropospheric temperature over the Eurasian continent, Q. J.R. Meteorol. Soc., 127, 909-937, 2001.

Livezey, R. E., and W. Y. Chen, Statistical field significance and its determination by Monte Carlo techniques, Mon. Weather Rev., 111, 46-59, 1983.

Matsuyama, H., and K. Masuda, Seasonal/interannual variations of soil moisture in the former USSR and its relationship to Indian summer monsoon rainfall, J. Clim., 11, 652-658, 1998.

Meehl, G. A., W. M. Washington, D. J. Erickson III, B. P. Briegleb, and P. J. Jaumann, Climate change from increased $\mathrm{CO}_{2}$ and the direct and indirect effects of sulfate aerosols, Geophys. Res. Lett., 23, 3755-3758, 1996.

Parker, D. E., C. K. Folland, and M. Jackson, Marine surface temperature: Observed variations and data requirements, Clim. Change, 31, 559-600, 1995. 
Parthasarathy, B., A. A. Munot, and D. R. Kothawale, Monthly and seasonal rainfall series for all-India homogeneous regions and meteorological subdivisions: 1871-1994, in Contributions From Indian Institute of Tropical Meteorology, Res. Rep. RR-065, 113 pp., Indian Inst. of Trop. Meteorol., Pune, 1995.

Rasmusson, E. M., and T. H. Carpenter, The relationship between the eastern Pacific sea surface temperature and rainfall over India and Sri Lanka, Mon. Weather Rev., 111, 517-528, 1983.

Robinson, D. A., Weekly Northern Hemisphere snow maps: 1966-1999, Proceedings of the 12th Conference on Applied Climatology, Asheville, NC, p. 12, Am. Meteorol. Soc., Boston, Mass., 2000.

Robinson, D. A., K. F. Dewey, and R. R. Heim Jr., Global snow cover monitoring: An update, Bull. Am. Meteorol. Soc., 74, 1689-1696, 1993.

Robock, A., Ice and snow feedbacks and the latitudinal and seasonal distribution of climate sensitivity, J. Atmos. Sci., 40, 986-997, 1983.

Robock, A., and J. Mao, The volcanic signal in surface temperature observations, J. Clim., 8, 1086-1103, 1995.

Robock, A., C. A. Schlosser, K. Y. Vinnikov, N. A. Speranskaya, J. K. Entin, and S. Qiu, Evaluation of AMIP soil moisture simulations, Global Planet. Change, 19, 181-208, 1998.

Robock, A., K. Y. Vinnikov, G. Srinivasan, J. K. Entin, S. E. Hollinger, N. A. Speranskaya, S. Liu, and A. Namkhai, The Global Soil Moisture Data Bank, Bull. Am. Meteorol. Soc., 81, 1281-1299, 2000. (data available at http://climate.envsci.rutgers.edu/soil_moisture)

Schneider, S. H., and R. E. Dickinson, Climate modeling, Rev. Geophys., 12, 447-493, 1974.

Shinoda, M., Climate memory of snow mass as soil moisture over central Eurasia, J. Geophys. Res., 106, 33,393-33,403, 2001.
Thompson, D. W. J., and J. M. Wallace, The Arctic Oscillation signature in the wintertime geopotential height and temperature fields, Geophys. Res. Lett., 25, 1297-1300, 1998.

Vinnikov, K. Y., and A. Robock, Trends in moments of climatic indices, Geophys. Res. Lett., 29(2), 10.1029/2001GL014025, 2002.

Vinnikov, K. Y., A. Robock, N. A. Speranskaya, and C. A. Schlosser, Scales of temporal and spatial variability of midlatitude soil moisture, J. Geophys. Res., 101, 7163-7174, 1996.

Walker, G. R., Correlations in seasonal variations of weather II, Mem. Indian Meteorol. Dep., 21, 22-45, 1910.

Wallace, J. M., and D. S. Gutzler, Teleconnections in the geopotential height field during the Northern Hemisphere winter, Mon. Weather Rev., 109, 784-812, 1981.

Yang, S., and K.-M. Lau, Influences of sea surface temperature and ground wetness on Asian summer monsoon, J. Clim., 11, 3230-3246, 1998.

Yasunari, T., A. Kitoh, and T. Tokioka, Local and remote responses to excessive snow mass over Eurasia appearing in the northern spring and summer climate-A study with the MRI GCM, J. Meteorol. Soc. Jpn., 69, $473-487,1991$

M. Mu and A. Robock, Department of Environmental Sciences, Rutgers University, 14 College Farm Road, New Brunswick, NJ 08901-8551, USA. (mu@envsci.rutgers.edu; robock@envsci.rutgers.edu)

D. Robinson, Department of Geography, Rutgers University, Piscataway, NJ 08854-8054, USA. (drobins@rci.rutgers.edu)

K. Vinnikov, Department of Meteorology, University of Maryland, College Park, MD 20742, USA. (kostya@atmos.umd.edu) 

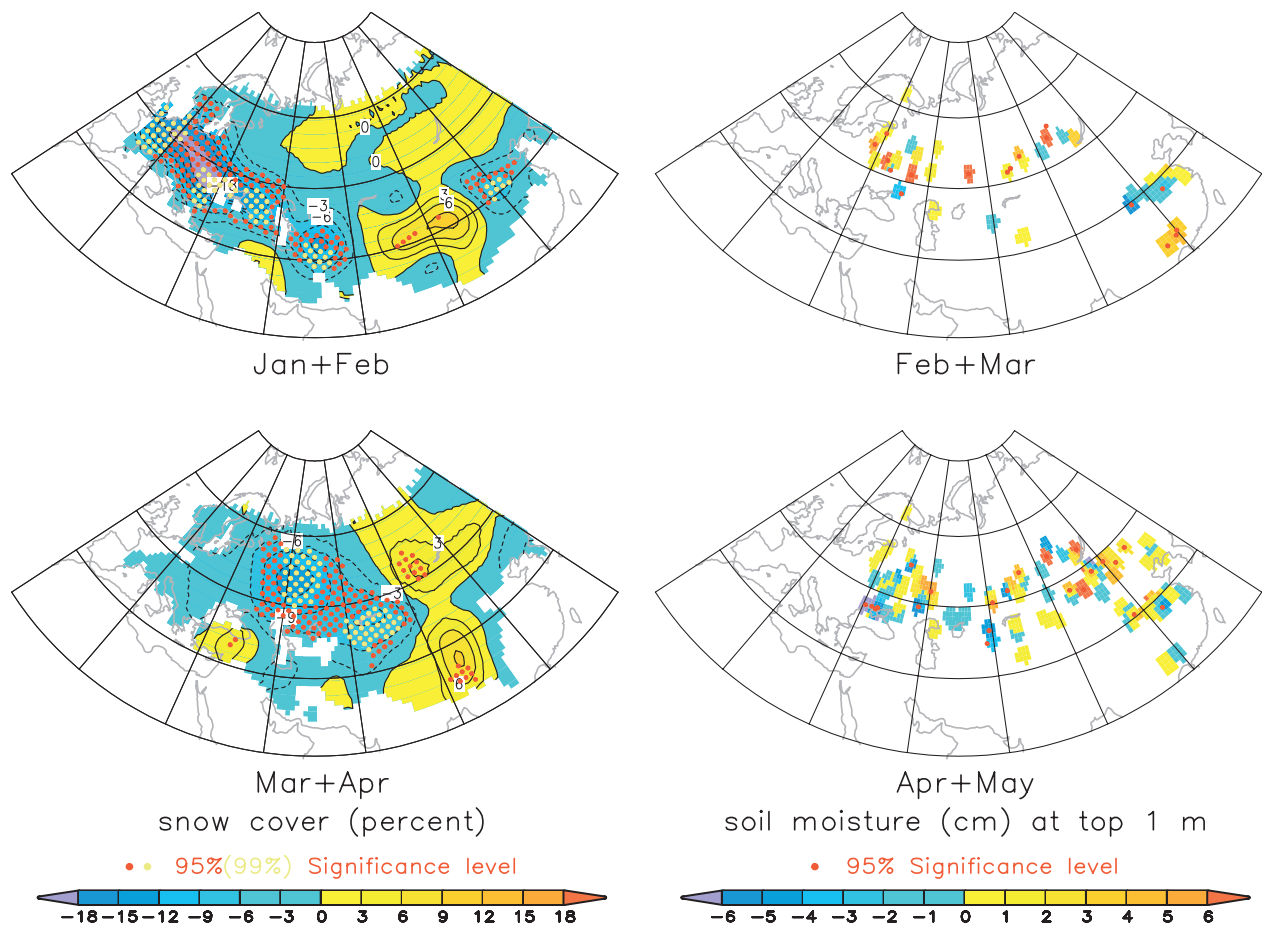
soil moisture $(\mathrm{cm})$ at top $1 \mathrm{~m}$

- $95 \%$ Significance level

$\begin{array}{lllllllllll}-18-15-12 & -9 & -6 & -3 & 0 & 3 & 6 & 9 & 12 & 15 & 18\end{array}$

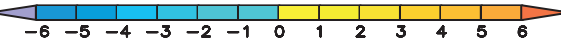

Figure 2. Composites of snow cover and soil moisture patterns for the winters and springs preceding summers of high all-India rainfall minus those of low all-India rainfall for the period 1967-2000. Areas significantly different from zero are stippled. 


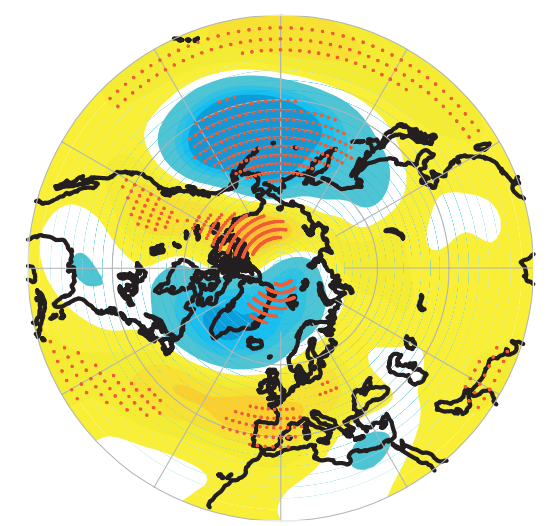

$500 \mathrm{hPa}$ Height $(M)$ in DJF
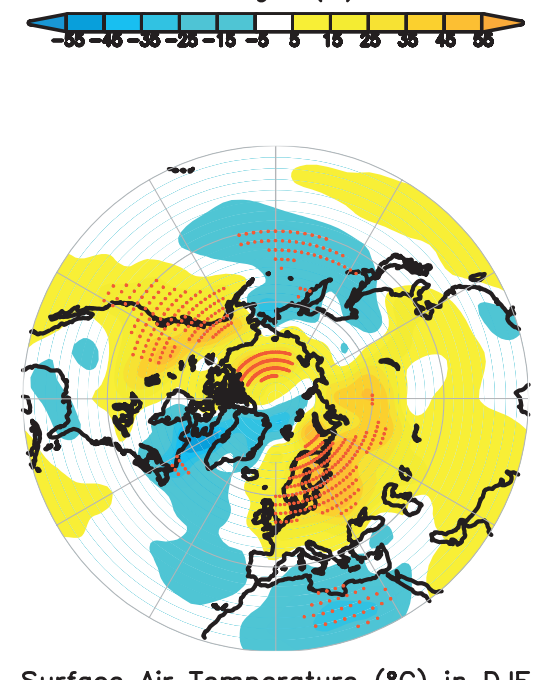

Surface Air Temperature $\left({ }^{\circ} \mathrm{C}\right)$ in DJF

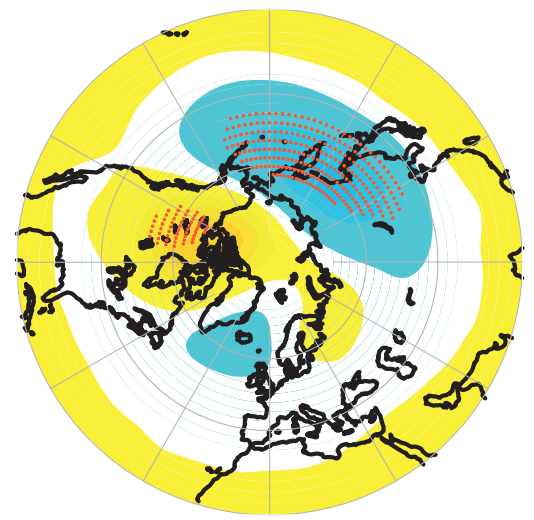

$50 \mathrm{hPa}$ Height (M) in DJF
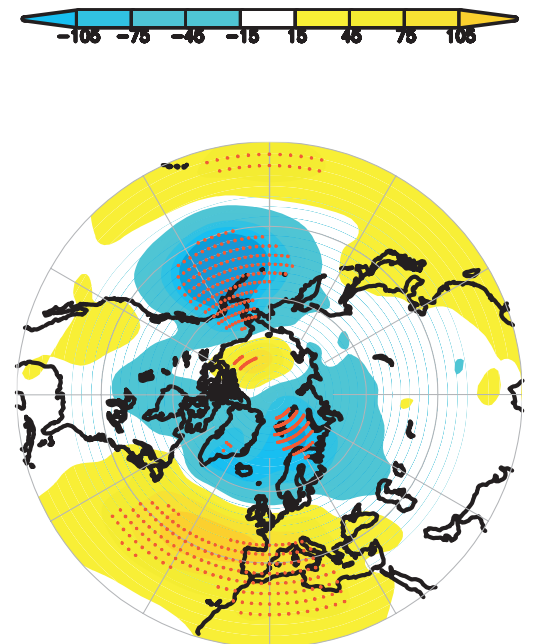

Sea Level Pressure ( $\mathrm{hPa}$ ) in DJF

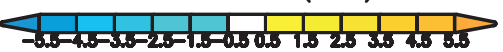

Figure 5. Composites of surface air temperature $\left({ }^{\circ} \mathrm{C}\right)$, sea level pressure $(\mathrm{hPa})$, and $500 \mathrm{hPa}$ and $50 \mathrm{hPa}$ geopotential height $(\mathrm{m})$ patterns for winters (DJF) preceding summers of high all-India rainfall minus those of low all-India rainfall for the period 1950-2000. Areas significantly different from zero are stippled (color version) or shaded (black and white version). 

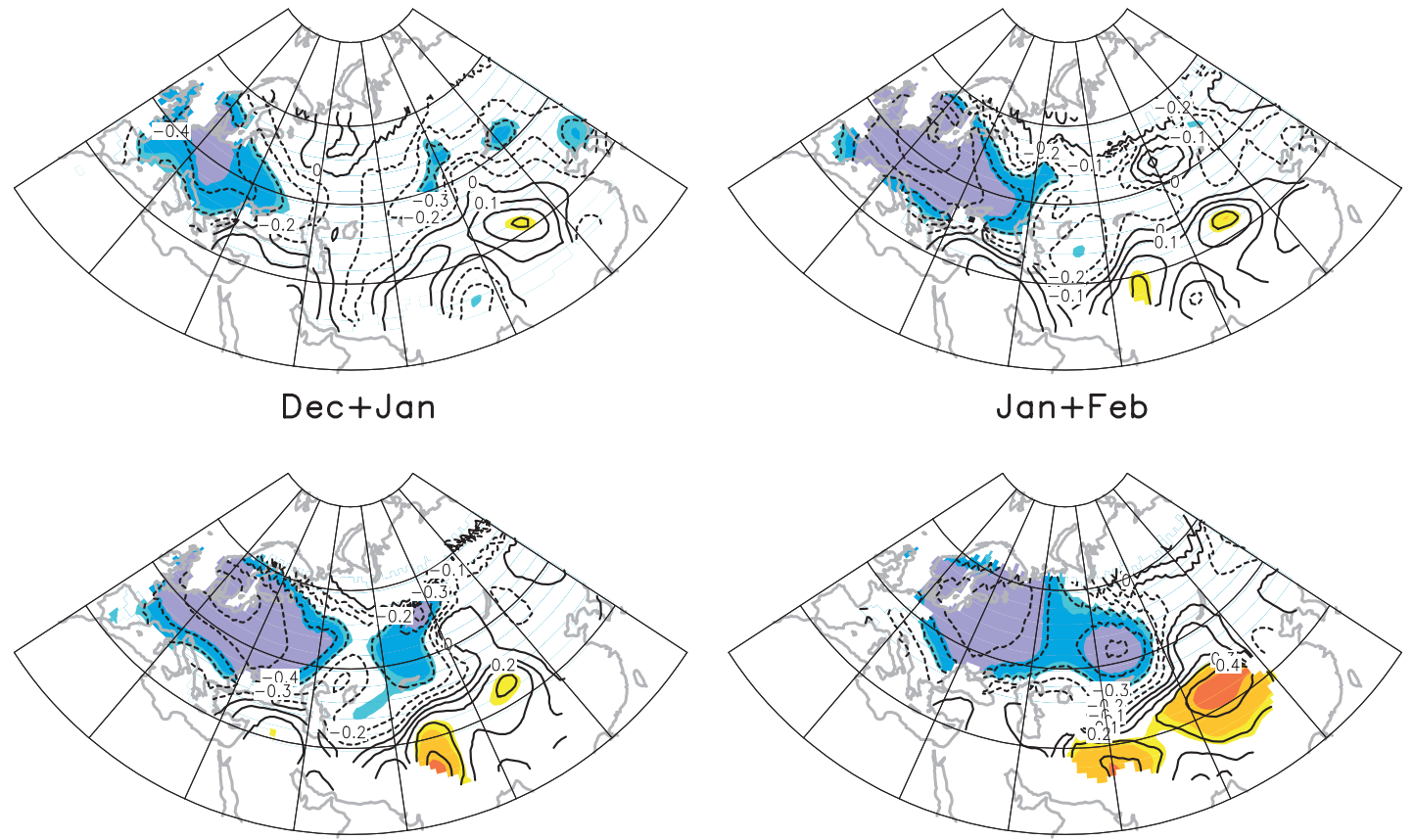

Feb+Mar

Mar+Apr

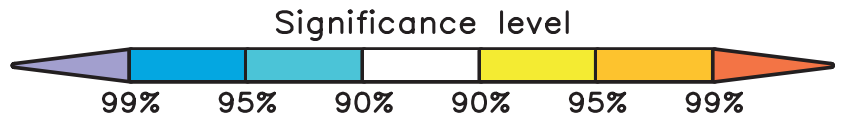

Figure 6. Correlations between detrended snow cover for 2-month periods indicated and the winter (DJF) North Atlantic Oscillation index for the period 1967-2000. Areas significantly different from zero and their significance levels are indicated. 


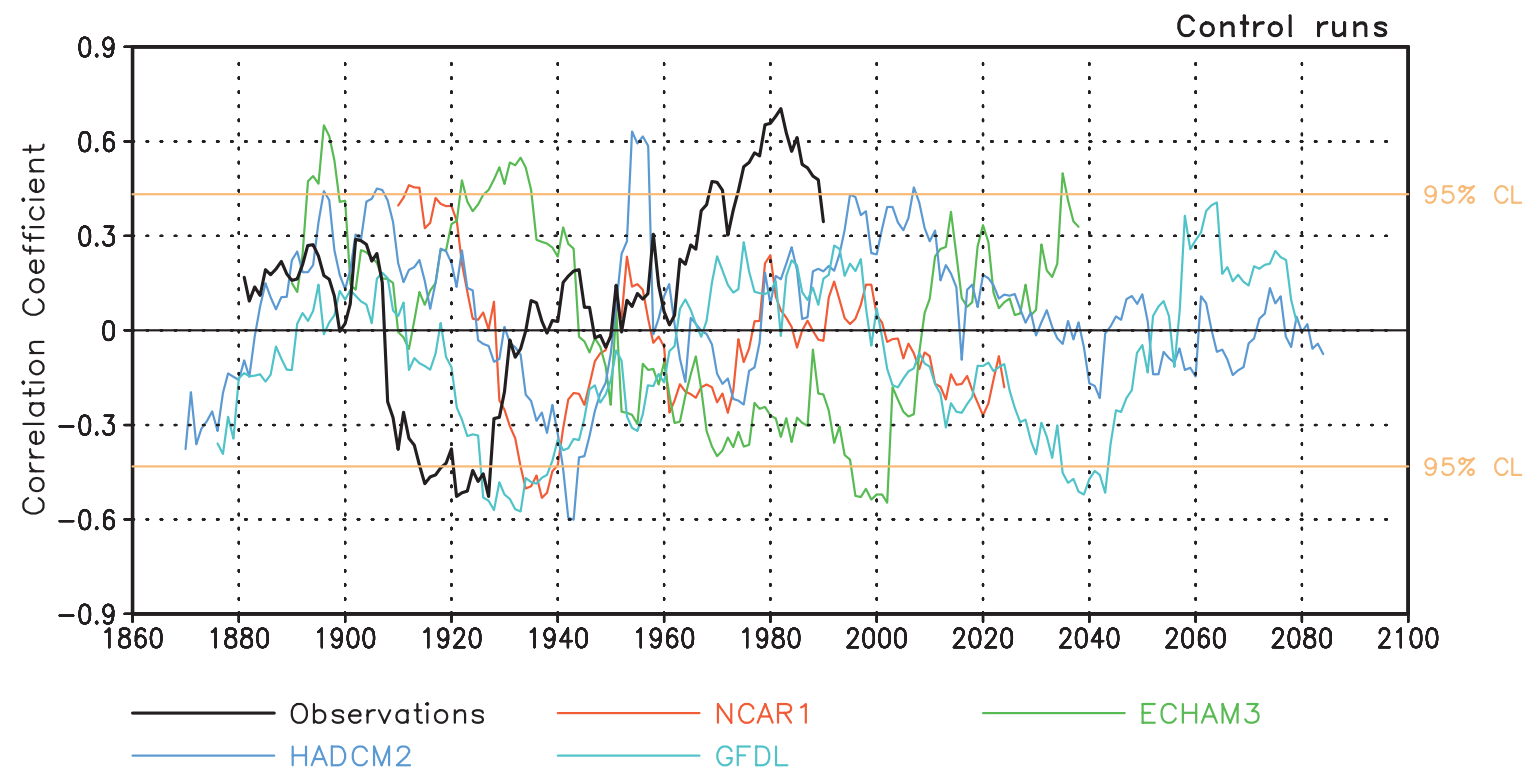

Figure 11. The 21-year running mean correlation between NAO and AIR for observations (repeating curve in Figure 9) and for control runs of four general circulation models (GCMs) (Table 1).

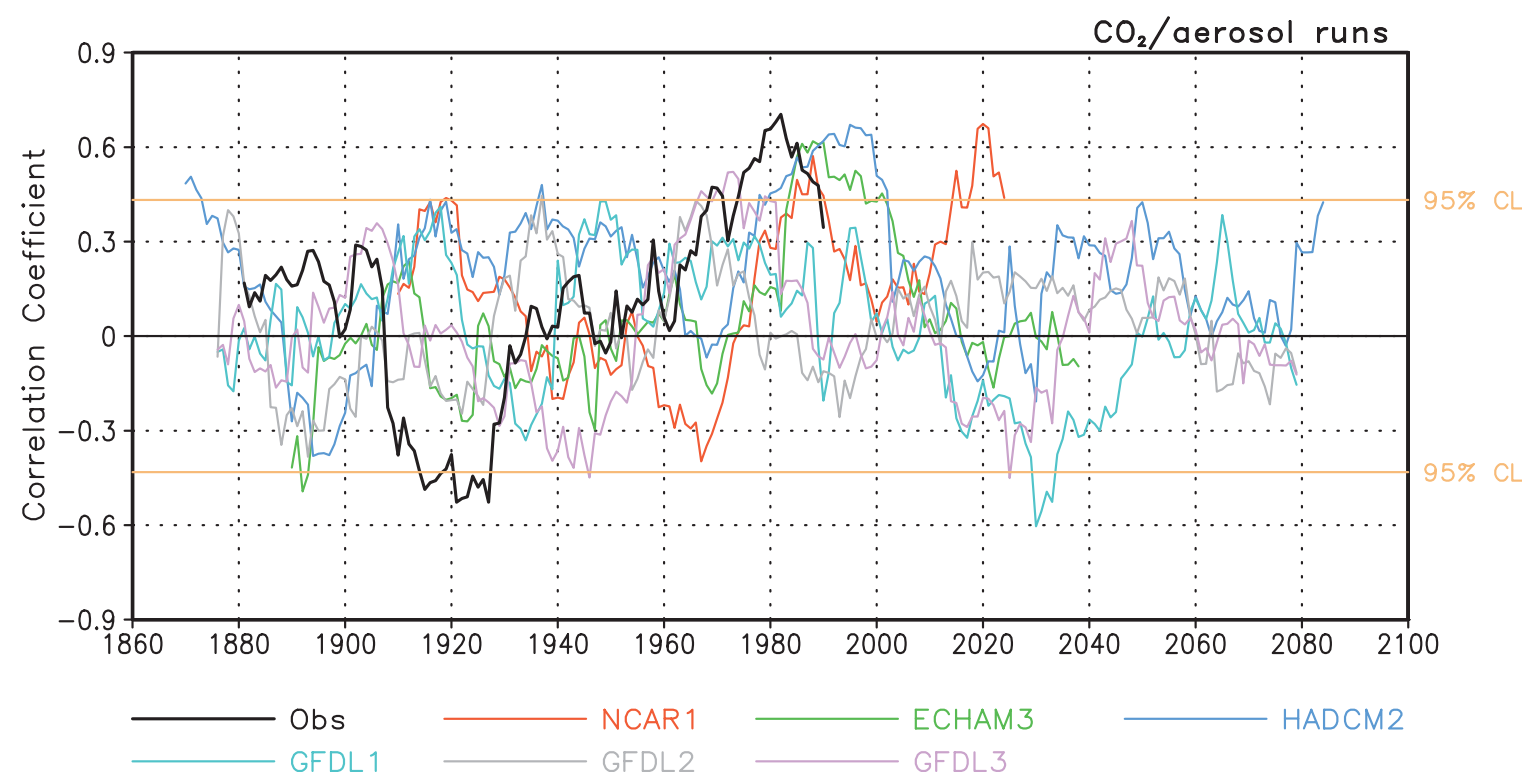

Figure 12. The 21-year running mean correlation between NAO and AIR for observations (repeating curve in Figure 9) and for runs of four GCMs (Table 1) forced with observed equivalent $\mathrm{CO}_{2}$ and tropospheric aerosols for the past and Intergovernmental Panel on Climate Change scenarios (Table 1) [Houghton et al., 1994] for the future. Three different Geophysical Fluid Dynamics Laboratory ensemble members are shown. 